\title{
Crop Technology Adoption Among Rural Farmers in Some Selected Regions of Mali
}

\author{
Ernest Kwaku Amponsah ${ }^{1}$, Emmanuel Aboagye ${ }^{2} \&$ Otuo Serebour Agyemang ${ }^{3}$ \\ ${ }^{1}$ Department of International Environment and Development Studies, Norwegian University of Life Sciences \\ (UMB), Norway \\ ${ }^{2}$ Institute for Applied Health Research, Ghana \\ ${ }^{3}$ Department of Economics and Management, University of Ferrara, Italy \\ Correspondence: Otuo Serebour Agyemang, Department of Economics and Management, University of Ferrara, \\ via Voltapaletto 11, Ferrara, Italy. Tel: 39-348-992-1968. E-mail: otuo.serebour.agyemang@gmail.com
}

\author{
Received: August 8, 2013 Accepted: August 30, 2013 Online Published: September 21, 2013 \\ doi:10.5539/jsd.v6n10p25 URL: http://dx.doi.org/10.5539/jsd.v6n10p25
}

\begin{abstract}
Enhancing farm production through an application of modern crop technologies to the extant farm system is relevant to improving the lives of farmers in rural areas. The Ecofarm crop technologies are some of the technologies that have been introduced with the aim of improving the lives of rural farmers in Mali. The study was carried out to examine the elements that influenced the adoption decisions of Ecofarm technologies among rural farmers in three selected regions of Mali. It contributes to the present knowledge on the socioeconomic factors that influence farmers in their adoption decisions of crop technologies in dry-land crop growing areas. Through the application of a multi-stage sampling technique, data were collected from 120 rural farmers from the three study regions. The Ordinary Least Square (OLS) and Cost-Benefit analyses were employed to analyze the data. It was evident that household size positively determined the adoption decisions of rural farmers in these regions. Also, the distance to these Ecofarm technologies had influence on the adoption decisions in that, the proximity of these technologies to the farms induced the rural farmers to adopt them. Interestingly, it was also found out that the larger the land holding of the farmers, the less likely it was for them to adopt the Ecofarm technologies. It was concluded that the regions with greater net benefits after the adoption were adopting more of Ecofarm crop technologies than those with less net benefit.
\end{abstract}

Keywords: crop technology, technology adoption, rural farmers, Ecofarm technologies, sahel region, Mali

\section{Introduction}

\subsection{Statement of Problem}

The Sahel region in Africa is a semi-arid region that lies between the Sahara desert and the Savanna region. This region extends over $6000 \mathrm{Km}$ from the Atlantic coast of Senegal and Mauritania to the Southern edge of the Sahara desert. It cuts across ten countries and it is a home to approximately 50 million people. Most of the people who live in this region practice subsistence farming. However, these farmers face countless problems in their farming activities thereby affecting their lives and the lives of their dependants. It is a region which is characterised by 9 -month dry season. Poverty is prevalent and the food productivity rate of $2 \%$ per annum is less than the population growth rate of $3 \%$ per annum (Bayala, Kalinganire, Tchoundjeu, Sinclair, \& Garrity, 2011)

One of the countries in this region that shares these characteristics is Mali. Although Mali is making some progress in reducing hunger and poverty, it is still considered as one of the poorest countries in the world. Persistent food insecurity and undernourishment continue to be endemic across the length and breadth of the country. Recently, Mali has urbanized quickly, but about $70 \%$ of its population still lives in rural areas, where poverty is rife and the vast majority of people depend on agriculture for food and income (IFAD, 2011). However, as a result of prolong dry season, farmers in the rural areas of the country are not able to produce as expected of them. In addition, poor soil quality and limited access to agricultural inputs are challenges that hinder farming in the rural areas. It is evident that rural farmers in Mali essentially depend on the traditional system of shifting cultivation to replenish the fertility of the soil and productivity increment (Samaké, 2003). 
In addressing the issue of how the fertility of the soil could be enhanced to ensure an increase in agricultural productivity in rural areas of Mali, a programme, named Ecofarm was introduced by the Drylands Coordination Group sponsored by Norwegian Agency for Development Cooperation (NORAD) to test how low cost agricultural technologies could increase agricultural productivity in some selected areas. The technologies tested on the farmers field included: 1) crop technologies, which consisted of seed priming to smoothen seed germination and fertilizer microdose, 2) animal husbandry technology, which consisted feeding livestock with millet bran and cowpea hay, 3) human nutrition enhancement technologies, which focused on the cultivation and feeding of altered Moringa oleifera and Baobab and 4) agroforestry technologies, which was centred on planting trees particularly, enhanced Ziziphus Mauritiana, and the of establishment of garden with Acacia niolitica and Acacia tumida. Despite the availability of these technologies, farmers were not forced to apply these technologies in their farms, but rather had the chance to choose and decide on which of the technologies were best for them.

The decision of a farmer on whether or not to use a newly introduced technology or otherwise can be regarded as a choice between two available technologies. In this case, the rural farmers were exposed to low cost agricultural technologies, but their decisions as to whether to adopt them or otherwise were influenced by certain factors. And these factors explained the variance between the groups of adopters and non-adopters. While farm tests have been carried out on these Ecofarm technologies in Mali (Traore et al., 2010), little is known about the factors that influenced the adoption decisions on the Ecofarm technologies of rural farmers in Mali. It is therefore of importance for research to be undertaken to better appreciate the elements that influenced the adoption decisions of rural farmers in relation to the Ecofarm technologies. This study sought to assess the factors that influenced the adoption of Ecofarm technologies among rural farmers in Mali.

The paper is structured in the following manner. In section 2 the study's literature is presented. Section 3 discusses the methodology of the study. In section 4 the study's result and discussion are presented. Finally, section 5 concludes the study with policy implications.

\section{Literature Review}

Conventional study on how farmers adopt new technologies gives explanations to the adoption decision and its regulation of occurrence (ie. whether near the beginning or behind schedule) essentially in relation to the decision maker's perceptual experience and innate characteristics, with 'straggler' at one end and 'innovator' at the other (Rogers, 1995). But usually, a farmer's decision-making process in regards to an adoption of new technologies is byzantine. This is because farmers have several objectives (such as social security, food security, sufficient income, a secure asset and so on) and circumspectly choose 'livelihood strategies' that would help them in their pursuance of these multiple objectives with their limited available resources (Ellis, 1997; Scherr, 1995). It is also worth to consider that both the available limited resources and the multiple objectives of the farmers differ among them and alter over life-cycle of farm household. Corollary to this, farmers who reside within the same environ will probably have differing objectives and livelihood strategies. This then makes them to react distinctively to an introduction of new technologies.

The conventional study into farmers' adoption also streamlines the analytical thinking of the adoption decision by its underlying assumption of the decision-process of a person. The capability of a farm household to take decisions in relation to technology and resource use differs with respect to age, education, sex, inter alia, and concrete decisions can be made subject to an agreement among members of the farm household (Fufa \& Hassan, 2006; Gardebroek, 2002; Jackson, 1995; Ellis, 1993). Transcending the farm household, group processes and capability to harness them can also play a significant role in adoption decisions of farmers chiefly, in regards to conservation practices (Gardebroek, 2002; Chamala \& Keith, 1995; Pretty \& Shah, 1994; Frank \& Chamala, 1992). More so, adoption decisions on new technologies are often prompted by an intervention, particularly, projects. Such projects attract farmers into a broader ground in which a gamut of socioeconomic factors influence them to pursue their personal strategies. The result regarding the adoption decisions will be dependent on the interaction among these socioeconomic factors.

Therefore, a factor-oriented standpoint will lead us to anticipate a gamut of responses in regards to the introduction of new agricultural technologies like Ecofarm technologies, not just a straightforward decision to adopt or otherwise. The differences between the communities that farmers live, farmers' goals, other socioeconomic circumstances, group that they belong to, project interplay and decision-making processes, will lead to a wide range of adoption behavior, which should be critically examined on their own terms and not jump to conclusions. 


\section{Methodology}

\subsection{Study Area}

The study was conducted in Segou, Mopti and Koulikoro regions located in Mali, between latitudes $10^{\circ}$ and $25^{\circ} \mathrm{N}$ and longitude $13^{\circ} \mathrm{W}$ and $5^{\circ} \mathrm{E}$. The region of Segou covers a surface area of about $64,821 \mathrm{Km}^{2}$ and it is bordered to the south by Sikasso region, to the east by Mopti region and to the west by Koulikoro region. The population of Segou region is about 2,336,255. In the case of Mopti, the region covers a land surface of 79,017 $\mathrm{Km}^{2}$ with a population of about $2,037,330$. The region of Koulikoro covers a land surface of $95,848 \mathrm{Km}^{2}$ with a population of about $2,418,305$.

The climatic condition of Mali ranges from tropical in the south to arid in the north. The Segou region experiences a semi-arid climate with an average rainfall of about $513 \mathrm{~mm}$. It has two seasons; the wet and dry seasons. In the case of Mopti, the region experiences quite warm temperature with an average rainfall of about $400 \mathrm{~mm}$. Koulikoro experiences relatively higher amount of rainfall as compared to these two regions. Its annual rainfall ranges between $600 \mathrm{~mm}$ in the northern part of the region and $1000 \mathrm{~m}$ to the southern part.

The main economic activity in the Segou region is agri-business. The pastoral system of production is dominant in the region. The region's agricultural activities have concentrated in the production of cereals. Just like Segou, Koulikoro's economic activities are dominated by agri-business. Its agricultural activities are also dominated by the production of cereals. Animal husbandry is also one of the major agricultural activities in the Koulikoro region. The Mopti region is also characterised by sedentary farming and livestock activities.

\subsection{Data Collection}

The principal data used for this study were gathered from a cross-sectional survey and was carried out using a semi-structured questionnaire to get hold of catholic data in regards to household characteristics and the elements that influence farmers' adoption decisions. Cross-section analysis was applied because the researchers wanted the farmers to answer important questions about technology use. It helped the researchers to ascertain the decision-making processes of the farmers-by asking them about the factors that influenced their choices of technologies. Through the cross-sectional survey, the researchers were also able to establish the preferences of the farmers in regard to the technologies. Finally, it helped the researchers to determine those technologies that have been tried and discarded by the farmers.

\subsection{Sampling Technique and Sample Size}

Multi-stage sampling technique was applied in this study. Rural communities in Segou, Koulikoro and Mopti regions which were exposed to the Ecofarm technologies were purposefully selected. This was successfully carried out through the assistance of NORAD. The farmers in these communities in each of the regions were stratified into two groups: those who adopted the technologies and those who did not. Finally, through a simple random sampling technique, $10 \%$ of adopters in each of the three regions were selected. This was done to ensure fair representation across the three regions. In all, 120 farmers were selected from the three study regions: 40 were selected from the Segou region, 38 from the Mopti region and 42 from the region of Koulikoro.

\subsection{Methods of Analysis}

Data collected were analyzed using descriptive statistics (mean and percentages). Household characteristics and socio-economic status of the farmers particularly, farm size, household size and distance to fertilizer were descriptively analysed. Also, in order to establish the relationship between household characteristics and socio-economic factors, and adoption decision, an Ordinary Least Square (OLS) regression analysis was employed. Different forms of OLS regression analysis were used to ascertain the model that offers the best fit to the data. Finally, the study employed a cost-benefit analysis to ascertain the influence of revenue on adoption decisions of the farmers and this was carried out based on the perspectives of the farmers. This is because the adoption of newly-introduced technologies is financially driven thus newly-introduced technologies that contribute immensely to the farmers income are likely to be adopted by farmers. In simple terms, if the expected contribution of income from the farm exceeds that of other activities, farmers are more inclined to adopt newly-introduced technologies.

\subsection{Regression Analysis}

In order to analyse the relationship between the household characteristics and socio-economic factors, and the degree of adoption of the farmers in the three regions, the OLS method of regression was applied. Four functional forms (that is, linear, semi-log, double log and exponential forms) were applied to ascertain the model that offers the best fit to the data. The general form of the OLS is highlighted below: 
Linear form

Exponential form

$$
\mathrm{Y}=\beta_{0}+\beta \mathrm{F}_{\mathrm{t}}+\mathrm{e}_{\mathrm{t}}
$$

$$
\log Y=\beta_{0}+\beta F_{t}+e_{t}
$$

Semi-log form

$$
\mathrm{Y}=\beta_{0}+\beta \log \mathrm{F}_{\mathrm{t}}+\mathrm{e}_{\mathrm{t}}
$$

Double-log form

$$
\log Y=\beta_{0}+\beta \log F_{t}+e_{t}
$$

Where, $Y$ is the endogenous variable. $\beta_{0}$ is constant, $\beta$ is the coefficient of the exogenous variables, $F_{t}$ is the exogenous variables and $e_{t}$ is the disturbance term. The choice of an appropriate regression function was dependent on the statistical measure of performance such as the significance of the parameters of the exogenous variables, the signs of the parameters of the exogenous variables, whether or not they support the a priori expectations and the adjusted $\mathrm{R}^{2}$. The higher the $\mathrm{R}^{2}$ the better the function appropriately gives better results.

Given the complexity that is associated with the indicators that can better be used to measure adoption (Doss, 2006); the researchers relied on the quantity of fertilizer (microdosing) use as a proxy to adoption in this study. The definitions and the a priori expectations of the parameters of the exogenous variables are discussed below.

The exogenous variables were, respectively, the age of the farmer, gender of the head of the household, farm size, level of education of farmers, household size and market access. The expected sign of age is empirically questionable in that it will probably be that farmers who are older have more experience in regards to cultivation and can easily be able to evaluate the features of a newly-introduced technology than younger ones (Doss, 2006; Adesina \& Forson, 1995). However, this will possibly be counterbalance by the innovative acumen by younger farmers. Also, it could be possible that farmers who are older are more risk averse than the younger ones and are less likely to adopt newly introduced technology. Corollary to these arguments, there is no agreement in the extant art of knowledge on this as the direction of the impact is usually contingent on a specific technology or location (Doss, 2006; Adesina \& Forson, 1995; Polson \& Spencer, 1991).

Gender of the household head also influences the adoption decisions of farmers. The study introduced a dummy variable ( $1=$ male-headed household, $0=$ female-headed household) to indicate whether the gender of household heads could possibly influence the adoption decisions of farmers. The study assumed that the head of the household was a farmer as well as the main decision-maker. A study by Doss and Morris (2001) in Ghana suggests that male-headed households are able to access resources needed to use enhanced or newly-introduced technology better than their female-headed counterparts. Also, a study by Yu, Nin-Pratt, Funes and Gamessa (2011) in Ethiopia reports that accessibility to a newly-introduced or improved technology is better among male-headed households than their female-headed counterparts. It is therefore, expected that male-headed farm households are likely to access the Ecofarm technologies than their female-headed counterparts.

Furthermore, the level of education of farmers may influence the adoption decisions of farmers in regards to newly-introduced technologies or enhanced technologies. This variable was measured by the number of years of education of farmers (Boahene, Snijders, \& Folmer, 1999). Doss (2006) argues that farmers with higher levels of education are more inclined to adopt newly-introduced technology than those with lower education. A panel study by Endale (2011) in Ethiopia report that the level of education of farmers does influence the adoption decisions in regards to newly-introduced technologies. Yu, Nin-Pratt, Funes and Gamessa (2011) in their study on cereal production and technology adoption in Ethiopia also find that the level of education of farmers is likely to have a positive effect on adoption of a newly-introduced technology.

Farm size is also considered as a factor that influences adoption decisions of farmers. Farm size was measured in hectares in this study. The relationship between farm size and technology adoption varies from country to country (Gardebroek, 2002). But the hypothesis is that there is a positive relationship between farm size and adoption of newly-introduced technologies by farmers (Gardebroek, 2001; Adesina \& Forson, 1995).Wetengere (2009) in a study on fish farmers in Tanzania finds that farm size has a positive effect on adoption. Therefore, it is expected that farm size is likely to have a positive influence on adoption of newly-introduced technologies.

Moreover, household size can possibly influence the adoption decision of farmers. The correlation between household size and adoption of new technologies should be positive. Household size was measured by the total number of adult household members. Following Yu, Nin-Pratt, Funes and Gamessa (2011), the study assumed that with labour being a safe asset, compared to crop production, more family labour corresponds to a higher 
level of nonstochastic assets, allowing for adoption of new technologies. A study by Wetengere (2009) in Tanzania reports that household size has positive effect on adoption. This implies that farmers with bigger household sizes are more likely to adopt newly-introduced technologies. Therefore, it is expected that household size is likely to have a positive effect on access to newly introduced technologies.

Finally, market access is likely to influence the adoption decisions of farmers. Doss (2006) argues that areas with greater level of market access are more inclined to adopt new technologies in that market access is relevant for buying inputs and selling outputs. Market access in this study was measured by the distance to the nearest major market. It was measured in kilometres. It is expected that market access will positively influence the adoption of newly-introduced technology.

\section{Results and Discussion}

\subsection{Description of Household Heads}

The household characteristics of the Ecofarm site (area) studied and elements discussed in the literature that could influence adoption decision-making processes of farmers in the three regions are presented in Table 1 below. On the whole, the average (SD) age of participants was 47(9) years old. The average household size was 11 members. This number included typically household heads, wife(s) and husband(s), and other adult members of the household. Male farmers (who were household heads) participants dominated making $70 \%$ as opposed to $30 \%$ female participants. Only $37 \%$ of participants had formal education and the remainder (63\%) had no form of education from primary to higher levels of education.

Table 1. Characteristics of household heads $(\mathrm{N}=120)$

\begin{tabular}{cc}
\hline Feature & Frequency (\%) \\
\hline Age & $120(100)$ \\
Mean (SD) & $47(9)$ \\
Gender & \\
Male heads & $84(70)$ \\
Female heads & $36(30)$ \\
Level of education & \\
No education & $76(63)$ \\
7- 20 yrs education & $44(37)$ \\
Household size & $120(100)$ \\
Mean (SD) & $11(19)$ \\
Farm size (hectares) & $120(100)$ \\
Mean (SD) & $12(10)$
\end{tabular}

The mean land size holding was 12 hectares per household. The land holdings varied from region to region because of the availability of agricultural land for farming in each region. Segou had more arable land followed by Mopti and then Koulikoro.

\subsection{Adoption of Ecofarm Crop Technologies}

Among the various fertilizer application technologies introduced in the three regions, two were for crop production: microdosing and seed priming. These two crop fertilizer application technologies are processes whereby fertilizer is either fixated around the root of the crop (microdosing) or seeds soaked in water (seed priming) before cultivation. The implication was that the quantity of fertilizer use was therefore, important in explaining adoption decisions of farmers. Also, since it was possible that one farmer could be growing more than one crop (i.e mainly millet, sorghum, maize and so on), it was common to find farmers adopting more than one technology on the same farm but on different crops. Of the 120 farmers that participated in the study, $68 \%$ of the farmers responded positive to using microdosing while another $51 \%$ were using seed priming as shown in Table 2. Other technology types commonly used besides the two mentioned above were; composting (47\%), plant in line (35\%), Zai (19\%) and half-moon (18\%). 
Table 2. Type of crop technologies adopted by farmers

\begin{tabular}{cc}
\hline Type of crop technology & Farmers adopted (percent) \\
\hline Plant in line & $35.0 \%$ \\
Fertilizer microdosing & $67.5 \%$ \\
Zai & $19.2 \%$ \\
Seed priming & $50.8 \%$ \\
Compost & $46.7 \%$ \\
Half Moon & $18.3 \%$ \\
\hline
\end{tabular}

While $70 \%$ of male farmers adopted fertilizer microdosing, $61 \%$ of female farmers adopted fertilizer microdosing. Also, female farmers (52\%) adopted more seed priming than their male (50\%) counterparts. This implies that on one the hand, male farmers adopted more microdosing as compared to female farmers. On the other hand, female farmers adopted more seed priming than their male counterparts. The gender differences in adoption of microdosing and seed priming could be attributed to cost and the amount of workload involved in using the two technologies.

With regards to household size, the adoption of crop technologies increased with the number of adult members that constitute a particular household. Also, farmers with larger land holdings tended to adopt less crop fertilizer technologies: microdosing and seed priming. For instance, $72.5 \%$ of household heads with smaller land size (1-10 hectares) adopted fertilizer microdosing as compared to $57.1 \%$ of those with larger land size (20 and above hectares). The trend was similar in the case of seed priming with $64 \%$ of farmers with smaller land size adopting the technology while only $36 \%$ of those with larger land size ( 20 hectares and above) adopting the seed priming.

This situation was also evident at the regional level. Segou had the highest average land size of 18.0 hectares, but only 1.1 hectares and 1.2 hectares on average were used for microdosing and seed priming respectively. On the other hand, out of an average of 4.9 hectares per households in Koulikoro, an average of 2.2 and 2.8 hectares of land applied microdosing and seed priming technologies respectively. Of the 11.8 hectares of land on average available to each household in Mopti, an average of 4.8 hectares applied microdosing while 4.7 hectares were subject to the application of seed priming. However, the study observed that farmers with larger land holdings who could not afford to use these technologies cultivated on larger portions of land in order to obtain the same output as those applying the technologies on a smaller portions of land.

Market access was important for the adoption of the crop technologies not only in terms of distance to fertilizer sources but also it somehow set the prices of fertilizer and the quantity of fertilizer use. Table 3 below demonstrates that the distance to fertilizer sources determined the prices of fertilizer which in turn influenced the quantity of fertilizer use by the farmers.

Table 3. Distance to fertilizer sources, prices and quantity of fertilizer use

\begin{tabular}{cccc}
\hline Market access & Distance $(\mathrm{km})$ & Price of fertilizer (FCFA) $(\mathrm{kg})$ & Quantity of fertilizer \\
\hline Segou & 53 & 16138 & 73 \\
Mopti & 22 & 14638 & 139 \\
Koulikoro & 5 & 14200 & 209 \\
Mean & 27 & 14992 & 141 \\
\hline
\end{tabular}

\subsection{Factors Influencing the Adoption of Ecofarm Crop Technologies}

Table 4 highlights the estimated OLS regression function. It presents adoption (quantity of fertilizer use) as the endogenous variable $(\mathrm{Y})$ and socioeconomic factors-such as the age of the farmer, gender of the head of the household, farm size, level of education of farmers, household size and market access-as exogenous variables. The outcome of the regression analysis shed light on the extent the exogenous variables $\left(\mathrm{F}_{\mathrm{t}}\right)$ determined and explained the adoption of crop technologies in the three regions. These estimated results of the OLS regression function demonstrated that the double-log form function provided the best fit for the study's analyses. 
Table 4. Estimated OLS regression function on factors influencing adoption of crop technologies

\begin{tabular}{ccccccc}
\hline \multirow{2}{*}{ Independent variables } & \multirow{2}{*}{ Unstandardized coefficient $\beta$} & \multicolumn{5}{c}{ Standardized coefficient } \\
\cline { 3 - 7 } & & Std.error & Beta & Rsquare & $\mathrm{t}$ & sig \\
\hline Age Gender & -0.90 & 11.05 & -0.079 & 0.006 & -0.856 & 0.393 \\
Male-headed & 3.111 & 20.38 & -0.014 & 0.012 & -0.153 & 0.879 \\
Female-headed & -4.523 & 22.75 & -0.010 & 0.004 & -0.278 & 0.912 \\
Level of education & 11.270 & 16.64 & -0.051 & 0.073 & -0.677 & 0.500 \\
Farm size & -0.257 & 0.943 & -0.244 & 0.059 & -2.73 & $0.007^{*}$ \\
Household size & 1.924 & 0.751 & 0.299 & 0.053 & 2.560 & $0.012^{*}$ \\
Market access & -3.12 & 0.280 & -0.716 & 0.513 & -11.15 & $0.000^{*}$
\end{tabular}

Dependent variable: Quantity of fertilizer use; * significant $\mathrm{p} \leq 0.005 ; \mathrm{R}^{2}=0.531$.

The results highlighted that $53.1 \%$ of the variations in technology adoption were explained by the exogenous variables of the function. The coefficient of age from the regression analysis was negative but insignificant. This implied that the older the farmer, the lesser the adoption of crop technologies. As discussed earlier, this finding would probably stem from the assertion that older farmers tend to portray risk-averse attitude towards new technologies and their long experience with farming could influence the adoption of the crop technologies as compared to the younger farmers. This result is similar to that of Wetengere (2009) on fish farming technology adoption among fish farmers in Tanzania.

The positive sign of the male-headed household shows that as the number of male-headed households increases, technology adoption also increases Although the male-headed households were not significant in determining the adoption decisions of farmers in these regions, the positive sign of its coefficient was consistent with most extant studies on technology adoption that male-headed households are able to access resources needed and adopt new technologies more than their female-headed counterparts (Doss \& Morris, 2001; Yu, Nin-Pratt, Funes, \& Gamessa, 2011). The reason male-headed households seemed to adopt new technologies would probably be as a result of the participant selection process in this study or the traditional practice of seeing more males than females doing farming in some settings. On the other hand, the coefficient of female headed household was negative but not significant. This may as well stem from the assertion in the existing body of knowledge in regards to technology adoption that women do not have opportunities to access alternative sources of income and corollary to this, they are less likely to adopt new technologies (Wetengere, 2009).

The level of education of farmers measured by the number of years of education also did not influence the adoption decisions of farmers in regards to the newly-introduced technologies. The relation between education level and adoption decision of farmers was positive, but not significant. This implies that farmers with higher levels of education are more slanted to adopt newly-introduced technologies than those with lower education. This observation is in line with the works of Kimenye (2001) and Wetengere (2009) which show that farmers with formal education are more inclined to adopt newly-introduced technology. Even though the coefficient of the level of education was not significant, this observation does not seek to concretely conclude that the level of education of farmers do not influence the adoption of crop technologies. The possible explanation that can be given is that since most of the farmers were illiterates, their adoption levels were probably not influenced by their levels of education. Corollary to this, the level of education did not play an important role in determining adoption decisions of farmers in these regions.

Farm size was significant in determining adoption of technologies. As the sign of the coefficient indicated, farm size was inversely related to quantity of fertilizer use. Therefore, the larger the land holding of the farmer, the less likely it was for the farmer to adopt crop technologies. The coefficient of determination $\left(\mathrm{R}^{2}\right)$ of farm size owned was 0.059 which implied that farm size only explained $5.9 \%$ of the variations in adoption. The possible explanation may be that land holding may be correlated with income (which is also an indicator of wealth) of household heads and therefore, making farm size to explain less of the variability in the adoption crop technology. This result was not confirmed by the hypothesis that farm size is likely to have a positive influence on adoption of newly-introduced technology.

Household size measured by the total number of adult household members was significant and positively related to adoption of crop technologies. From the analysis, household size could account for $5.3 \%$ of the total variation 
in crop technology adoption. This outcome is consistent with the findings of $\mathrm{Yu}$, Nin-Pratt, Funes and Gamessa (2011) and Wetengere (2009) that additional adult members in a given household increase the possibility to adopt new technologies. The study found that adult members played a significant role particularly, when active members of households moved away from home to other ventures-a practice which is common in these regions.

Market access was significant in explaining technology adoption. A positive relationship between market access and adoption was established. This implied that the difficulty in getting access to fertilizer as a result of distance had a negative effect on the adoption of crop technologies. From the results, market access could explain $51 \%$ of the total variation in adoption in the three regions. This result is in agreement with the work of Doss (2006) which states that the greater level of market access positively influences the adoption of new technologies in that, market access is relevant for buying inputs and selling outputs.

\subsection{Income of Farmers and Adoption of Crop Technologies}

The adoption of a new crop technology can be driven by both farm and non-farm incomes of the farmer. Thus farmers are more inclined to adopt crop technologies if they are rich in terms of income or if their expected contribution of income from the farm exceeds that of activities and production inputs. Farm income and non-farm income can also reflect the financial capability of a farmer in buying external inputs. Based on these two variables in relation to income (farm and non-farm income), this section of the study would focus on the farmers' incomes, which are more reliable and can be estimated with less inconsistency. However, since non-farm income may be underestimated and also inconsistent, this section will rely only on farm incomes based on 'before' and 'after' scenarios of productivity changes that occurred with the introduction of the crop technologies. Therefore, this section of the analysis would be based on the first year of the introduction of the crop technologies. Table 5 below shows the yield of two important crops (millet and sorghum) before and after the introduction of Ecofarm technologies.

Table 5. Average yield effects on crops before and after adoption of crop technologies

\begin{tabular}{lcccc}
\hline \multirow{2}{*}{ Region } & \multicolumn{2}{c}{ crop yield (kg/hectare) for Millet } & \multicolumn{2}{c}{ crop yield (kg/hectare) for Sorghum } \\
& \multicolumn{2}{c}{ Microdosing } & Seed priming \\
\cline { 2 - 5 } & Before & After & 260 & After \\
\hline Segou & 240 & 855 & 155 & 805 \\
Mopti & 125 & 500 & 200 & 430 \\
Koulikoro & 70 & 930 & 275 \\
\hline
\end{tabular}

All other things remaining constant, productivity increases for both millet and sorghum after adoption of microdosing and seed priming were observed in all three regions. In almost all cases, the differences were large though the increases in productivity varied across the regions. Therefore, it was expected that this productivity would increase farmer's income (farm income) and as a result, farmers would be more likely to adopt the crop technologies. At this stage of the adoption decision making process, the study further assumed that farmers would be less risk averse due to the information they had on crop yield from using fertilizer. This justified the use of only farm income for the rest of the discussion on the adoption of Ecofarm crop technologies.

Table 6 below highlights the net productivity changes as a result of the adoption of microdosing and seed priming for millet and sorghum growers. The method used was in several stages. First we summed up all the variable costs the farmers incurred during adoption of a technology (for instance, cost of the fertilizer). Then, the benefits gained from the adoption of the technology were also estimated. Then again, the net benefit of adopting the technology was estimated from the difference between total variable cost and the gross benefit. The decision rule was that, if the net benefit from the adoption of crop technologies was positive, farmers would be more inclined to adopt the technology. 
Table 6. Net-benefit from the adoption of crop technologies

\begin{tabular}{lccc}
\hline Region & Segou & Mopti & Koulikoro \\
\hline $\begin{array}{l}\text { Millet growers } \\
\text { Costs }\end{array}$ & & & \\
Cost of fertilizer & 16137 & 14637 & 14200 \\
Cost of labour & 10026 & 4000 & 12292 \\
Total variable cost & 26163 & 18637 & 26492 \\
Benefits & & & \\
Gross benefit & 171000 & 100000 & 186000 \\
Net-benefit & 144837 & 81363 & 159508 \\
\hline Sorghum growers & & & \\
Costs & & & \\
Cost of fertilizer & 16137 & 14637 & 14200 \\
Cost of labour & 10026 & 4000 & 12291 \\
Total variable cost & 26163 & 18637 & 26492 \\
Benefits & & & \\
Gross benefit & 201250 & 107500 & 68750 \\
Net-benefit & 175087 & 88863 & 42259 \\
\hline
\end{tabular}

From the analysis, both millet and sorghum farmers who applied microdosing and seed priming technologies had positive net benefit far greater than zero. This increased the chances of farmers to adopt these crop technologies. The positive net benefit derived by farmers from the adoption of Ecofarm technologies is also confirmed in the study of Traore et al. (2003). In their study, the authors indicated that farmers were more likely to adopt the Ecofarm technology based on the high income or revenue they gained after the adoption of the technology as compared to traditional practices. This result was also reinforced at the regional level in that, regions with greater net benefits adopted the Ecofarm crop technologies more than those with lesser net benefit. For instance, farmers in Segou adopted microdosing and seed priming more than farmers in Mopti and Koulikoro. Also, farmers in Mopti adopted the Ecofarm technologies more than farmers in Koulikoro.

\section{Conclusion}

The purpose of the paper was to examine the elements that influenced the adoption decisions of rural farmers in relation to Ecofarm technologies in three selected regions in Mali. It was evident that household size positively determined the adoption decisions of rural farmers in these regions. Also, the distance to these Ecofarm technologies had influence on the adoption decisions in that, the proximity of these technologies to the farms induced the rural farmers to adopt them. Interestingly, it was also highlighted that the larger the land holding of farmers, the less likely it was for them to adopt the Ecofarm technologies. Furthermore, the study also illuminated that the regions with greater net benefits after the adoption, adopted more of Ecofarm crop technologies than those with lesser net benefit. These evidences in regards to net benefit and additional information on crop technology adoption were observed in the three regions. Corollary to these aforementioned findings, the study recommends that market accessibility of these crop technologies ought to be enhanced by bringing these technologies closer to the farmers. Also, credit should be made available to farmers in these regions to aid them purchase these technologies. Finally, extension services should be enhanced in that, these services can help expedite scaling up in these regions.

\section{Acknowledgement}

This scientific article is one of the results of the research related to the poverty reduction and food security project (Ecofarm) in Mali funded by the Norwegian Agency for Development (NORAD). We owe a debt of gratitude to the Department of Environment and Development Studies (Noragric) of the Norwegian University of Life Sciences (UMB) for providing a travel grant for the field work. We appreciate comments on the research process from Jens Bernt Aune (Professor), Department of Environment and Development Studies of the 
Norwegian University of Life Sciences and the two reviewers. We are also grateful for the field support and logistics provided by the Drylands Coordination Group in Norway and the Mali Branch.

\section{References}

Adesina, A. A., \& Baidu-Forson, J. (1995). Farmers' perceptions and adoption of new agricultural technology: evidence from analysis in Burkina Faso and Guinea, West Africa. Agricultural economics, 13(1), 1-9. http://dx.doi.org/10.1016/0169-5150(95)01142-8

Boahene, K., Snijders, T. A. B., \& Folmer, H. (1999). An Integrated Socioeconomic Analysis of Innovation Adoption: The Case of Hybrid Cocoa in Ghana. Journal of Policy Modeling, 21(2), 167-184. http://dx.doi.org/10.1016/S0161-8938(97)00070-7

Chamala, S., \& Keith, K. (1995). Participative Approaches for Landcare. Brisbane, Academic Press.

Doss, C. R. (2006). Analyzing technology adoption using microstudies: limitations, challenges, and opportunities for improvement. Agricultural Economics, 34(3), 207-219. http://dx.doi.org/10.1111/j.1574-0864.2006.00119.x

Doss, C. R., \& Morris, M. (2001). How does gender affect the adoption of agricultural innovations? The case of improved maize technology in Ghana. Agricultural Economics, 25(1), 27-39.

Ellis, F. (1993). Peasant Economics: Farm Households and Agrarian Development (2nd ed.). Cambridge, Cambridge University Press.

Ellis, F. (1997). Household strategies and rural livelihood diversification. Paper presented at Annual Conference of Development Studies Association, University of East Anglia, Norwich, England, 11-13 September 1997.

Endale, K. (2011). Fertilizer Consumption and Agricultural Productivity in Ethiopia. EDRI Working Paper 003.

Frank, B. R., \& Chamala, S. (1992). Effectiveness of extension strategies. In G. Lawrence, F. Vanclay, \& B. Furze (Eds.), Agriculture, Environment and Society: Contemporary Issues for Australia, Melbourne, Macmillan, 122-140.

Fufa, B., \& Hassan, R. M. (2006). Determinants of fertilizer use on maize in Eastern Ethiopia: A weighted endogenous sampling analysis of the extent and intensity of adoption. Agrekon, 45(1), 38-49. http://dx.doi.org/10.1080/03031853.2006.9523732

Gardebroek, C. (2002). Farm-specific factors affecting the choice between conventional and organic dairy farming. Zaragoza (Spain), 28, 31.

IFAD. (2011). Enabling the Rural Poor to Overcome Poverty in Mali. Retrieved June 2, 2013, from http://www.ifad.org/operations/projects/regions/Pa/factsheets/mali_e.pdf

Jackson, C. (1995). Environmental reproduction and gender in the Third World. In S. Morse, \& M. Stocking (Eds.), People and Environment (pp. 109-130). London, UCL Press.

Kalinganire, A., Tchoundjeu, Z., Sinclair, F., \& Garrity, D. (2011). Conservation Agriculture with Trees in the West African Sahel: A Review. World Agroforestry Centre.

Kimenye, L. N. (2001). Understanding Low Rate of Technology Adoption by Women Farmer: A Case Study of the Determinants of Adoption of Improved Varieties by Women Farmers in Mbeere District, Kenya. JAST, 3(1), 2001.

Polson, R. A., \& Spencer, D. S. (1991). The technology adoption process in subsistence agriculture: The case of $\begin{array}{lllll}\text { cassava in Southwestern Nigeria. Agricultural Systems, } & 36(1), & \text { 65-78. }\end{array}$ http://dx.doi.org/10.1016/0308-521X(91)90108-M

Pretty, J. N., \& Shah, P. (1994). Soil and Water Conservation in the Twentieth Century: A History of Coercion and Control. Research Series No. 1, Rural History Centre, University of Reading.

Rogers, E. M. (1995). The Diffusion of Innovations (4th ed.). New York, Free Press.

Samaké, O. (2003). Integrated crop management strategies in Sahelian land use systems to improve agricultural productivity and sustainability: a case study in Mali (No. 47). Wageningen University and Research Centre.

Scherr, S. J. (1995). Economic factors in farmer adoption of agroforestry: patterns observed in Western Kenya. World Development, 23, 787-804. http://dx.doi.org/10.1016/0305-750X(95)00005-W

Traore, C. O., Aune, J. B., \& Sidibe, M. M. (2010). Final Report on the Ecofarm Project in Mali: Synthesis of the Four Years 2005-2009. DCG Report No. 7. 
Wetengere, K. (2009). Socio-economic factors critical for adoption of fish farming technology: The case of selected villages in Eastern Tanzania. Int J Fish Aquac, 1(3), 28-37.

Yu, B., Nin-Pratt, A., Funes, J., \& Gemessa, S. A. (2012). Cereal production and technology adoption in Ethiopia.

\section{Copyrights}

Copyright for this article is retained by the author(s), with first publication rights granted to the journal.

This is an open-access article distributed under the terms and conditions of the Creative Commons Attribution license (http://creativecommons.org/licenses/by/3.0/). 